chapter, the technique of making blood cultures in the second, and interpretation of the findings in the third. In the remaining chapters, the findings in various diseases are described, and their significance is discussed, full bibliographies being appended to each chapter and at the end of the book. It is of interest how seldom micro-organisms seem to invade the blood stream in health-so infrequently that the few positive results obtained by the author (in only four of 106 individuals examined) might well be accidental contaminations. The author, in fact, is so sure of her methods that perhaps she scarcely stresses sufficiently the need for adequate skin disinfection in the technique adopted, and the possibility of aerial contamination of the cultures made.

This book has been compiled by one who has had great experience in this field of work, and the record of her investigations here presented must prove of much value to the clinician and clinical pathologist.

R. T. H.

Complement or Alexin

By T. W. B. Osborn. Pp. xi +116. (London : Oxford University Press, 1937.) 7s. 6d. net.

COMPLEMENT or alexin, present in fresh normal 4 blood serum, is an 'agent' by means of which delicate specific tests may be performed for the laboratory diagnosis of many diseases and for the exact determination of various bacterial species. Although in daily use in the medical laboratory, and notwithstanding much research as to what it is, its exact nature still remains somewhat of a puzzle, and it has been variously regarded as being an enzyme, a manifestation of surface energy, a physical or physico-chemical state, a colloidal phenomenon. This book contains a most useful survey of the scattered but extensive literature upon complement and its action, and since Dr. Osborn has himself contributed to its study, he has been in a position to select the more relevant matter and to evaluate its trustworthiness. A bibliography, running into eleven pages, is appended.

R. T. H.

\section{Short Manual of Regional Anatomy :}

Written for the Medical Student as an Aid to a Rapid Revision of the Whole Subject. By J. A. Keen. Pp. vii +167. (London, New York and Toronto: Longmans, Green and Co., Ltd., 1937.) $5 s$. net.

$\mathrm{T}$ HE author of this little work, who was formerly prosector and demonstrator of anatomy at King's College, London, deserves the gratitude of the student, whose labours he has done much to alleviate by his concise but lucid exposition. The English terminology adopted in 1933, in which eponymous nomenclature is omitted, is used throughout, but the older terms beloved of the medical historian are also given, and the Latin and Greek derivations, of which most students are ignorant, are appended to each chapter. The text is liberally interspersed with excellent figures and diagrams.
Appendicitis :

a Clinical Study. By W. H. Bowen. Pp. xii +202 . (Cambridge : At the University Press, 1937.) 7s.6d. net.

THIS little work, which Sir Arthur Hurst in his introduction declares to be the most satisfactory review of the subject in the English language, is based on the author's experience at Guy's Hospital and elsewhere. Special chapters are devoted to the etiology, diagnosis, prognosis, varieties of the disease, treatment and post-operative complications. A series of fifty-one cases is appended, classified in three groups according as the treatment was successful or unsuccessful, or other lesions were found at the time of the operation. The book should appeal alike to the physician, surgeon, general practitioner and senior student.

\section{Miscellany}

The Biology of Human Conflict:

an Anatomy of Behaviour, Individual and Social. By Dr. Trigant Burrow. Pp. xl+435. (New York: The Macmillan Co., 1937.) 15s. net.

TN this study of human behaviour the method and 1 conditions of the inquiry upon which it is based are of no less interest and significance than the conclusions. The book is sponsored by the Lifwyn Foundation, a community formed for the purpose of this investigation at the instance, and under the inspiration, of the author. It consists of a number of individuals, male and female, socially and economically of varied but normal pursuits as ordinary citizens, who for sixteen years lived together as material for self- and communal-observation. The community was, in fact, the author's laboratory for the investigation of the fundamental causes which underlie the social maladjustments, of which insanity and criminality are among the most commonly encountered symptoms.

The point of view, or hypothesis, adopted by Dr. Burrow, which was thus submitted to examination, was based upon his previous experience of neuroses, suggesting that these and other evidences of conflict in behaviour are not abnormalities in a social environment which is predominantly sound, but indicate that the origin of the conflict is the elevation into a law of social conduct of the divorce between reality and the symbolism of the word by which reality originally was designated. The valid touch. stone of behaviour is not the symbolism of the word, but the functioning of the organism as an integral whole. When, for example, the familiar dilemma of the relative character of the standards of good and evil is examined by an observer, who includes himself as material for observation and experiment, it emerges that, through symbolism, what is in fact secondary has been made the basis of judgment.

We Live and Learn:

Addresses on Education. By Sir Josiah Stamp. Pp. vii + 214. (London : Macmillan and Co., Ltd., 1938.) $7 s$. $6 d$. net.

THE addresses printed in this volume cover a wide field. Consider their titles: graduation 